\title{
A Utility Function Explanation of the Empirical Behavior of Income Relative to International Reserves for Selected Economies
}

\author{
Pook Carson \\ Associate Professor \\ Department of Business Management \\ Salt Lake Community College \\ USA \\ James P. Gander \\ Professor Emeritus \\ Department of Economics \\ University of Utah \\ USA
}

\begin{abstract}
The purpose of this paper is to explore an economy-wide utility model to explain the empirical behavior of national income relative to international reserves for selected economies. The empirical behavior is taken as the observed optimal outcome from a macroeconomic general equilibrium model which is not specified here but presumed to exist based on the general literature covering the topic. The model uses an economy-wide preference (utility) function as its objective function of two variables, national income and international reserves. The empirical data consist of the ratio of income to reserves for a selected number of mature and developing economies over the time period 1970 to 2011. For mature economies, the ratio is trending upwards, while for the developing economies, the ratio is trending downwards. It is this phenomenon that we attempt to explain in terms of the relative strength of the utilities for income versus reserves. The policy implications are discussed briefly within the context of the existing literature on international reserves.
\end{abstract}

JEL classification: $\mathrm{C} 61 ; \mathrm{F} 3 ; \mathrm{F} 4$

Keywords: Utility Function, Income, Reserves, Empirical Ratios

\section{Introduction}

The purpose of this paper is to develop an a priori utility explanation of the actual empirical behavior of national income, $\mathrm{Y}(\mathrm{t})$, relative to the behavior of a nation's international reserves, $\mathrm{R}(\mathrm{t})$. The explanation will attempt to differentiate between the behavior of the income-reserve ratio, $\mathrm{Y}(\mathrm{t}) / \mathrm{R}(\mathrm{t})$, over time (in other words its dynamic behavior) for developing economies versus mature (or developed) economies. The essence of the utility explanation is an economy-wide utility function of the type $\mathrm{U}(\mathrm{Y}(\mathrm{t}), \mathrm{R}(\mathrm{t}))$ which is shaped by cultural preferences, the details of which will be forthcoming.

The utility explanation is presumed to operate within the context of an unspecified general macroeconomic optimization model which, in effect, would account for the empirical behavior of $Y(t)$ and $R(t)$ that we examine. We do not develop such a model here, for doing so would take us beyond the theme (or purpose) of the paper (see, for work on optimal reserve modeling, Alfaro and Kanczuk, 2009; Bar-Ilan, Marion, and Perry, 2007; and Costinot, Lorenzoni, and Werning, 2011).

Our explanation, in effect, is an ex post reason for the observed empirical behavior of the income-reserve ratio. This explanation has value for it attempts to get at the utility foundation of income/reserves behavior and why it differs among economies. This value hopefully will add to our understanding of the recent surge in international reserves (see, for a discussion, Vujanovic, 2011).

Much of the literature on the income-reserve ratio focuses on the need for self-insurance, but not particularly on the country-specific differences in Y/R ratios. Our model is designed to shed some light on these differences. 
The literature is very large and very current. Much of it is from the NBER, the OECD, and the IMF. It is concerned with reserves as self-insurance against sudden capital outflows, with the optimal level of reserves recognizing adjustment costs to "sudden stop" capital inflows (for example, when exports suddenly drop relative to imports), the opportunity cost (social cost) of holding reserves, the empirical determinants of reserves, the economic development role of reserves (the so-called Mercantilist effect), the policy issues related to imperfections in the current behavior of the IMF, the use of international reserves in managing a country's international debt, and probability models design to handle the optimal level of reserves under uncertainty. This is quite an array of topics, but it is not the purpose of this paper to survey this vast literature. For examples of surveys, see, Calvo, Izquierdo, and Loo-Kung (2012), Obstfeld, Shambaugh, and Taylor (2008, 2010), Moghadam (2010), and Vujanovic (2011). For an excellent set of references, see Jeanne (2007) and his model for determining the optimal level of reserves.

In the next section, we develop the utility function model. Then, in the following section, we undertake an empirical examination of the Y/R ratios for several developing and mature economies covering the time period 1970 to 2011. By choice, South East Asian countries are used to represent developing economies and the mature economies are represented by the major traders in South East Asia (the USA, Germany, and Japan). The last section has a summary and conclusions.

\section{The Utility Function Model}

The stock of international reserves, R(t), has four components: gold, special drawing rights, the IMF member's deposit, and foreign exchange holdings by the country's monetary authority. To simplify our explanation, we treat $\mathrm{R}(\mathrm{t})$ as homogenous financial capital and use it in aggregate form. The stock of reserves is essentially generated by a nation's exports of goods and services relative to its imports (in other words, by the current account in the balance of international payments).

The surplus on the current account can have several different uses (as the above literature topics suggest), such as adding to a country's loanable funds supply via the banking system, or purchasing foreign bonds (like China does), or adding to its reserve account holdings within its own central bank or the IMF, or reducing its international debt. While these different uses have different implications with respect to a country's income (GDP), pursing these implications is beyond the scope of our paper, for we use aggregate reserves to focus on the utility explanation of the behavior of income and reserves and take its multiple uses as given.

The utility function is given by $\mathrm{U}=\mathrm{U}(\mathrm{Y}(\mathrm{t}), \mathrm{R}(\mathrm{t}))$ and, as indicated earlier, it includes the country's flow variable, $\mathrm{Y}(\mathrm{t})$, and its asset variable, $\mathrm{R}(\mathrm{t})$. The use of $\mathrm{Y}$ or $\mathrm{C}$ (consumption) in an economy's $\mathrm{U}($.$) is common. Our inclusion$ of an asset $\mathrm{R}$ in $\mathrm{U}($.$) is an important design feature. The presumption is that the \mathrm{R}$ (and its various unspecified uses) also creates utility much like $\mathrm{Y}$ does with its various unspecified components. Other assets may also create utility, but their inclusion would complicate the model and would go beyond the focus of the paper.

Standard properties for $\mathrm{U}\left(\mathrm{Y}(\mathrm{t}), \mathrm{R}(\mathrm{t})\right.$ ) are assumed. Let $\mathrm{i}$ index $\mathrm{Y}$ and $\mathrm{j}$ index $\mathrm{R}$, so that the partial derivatives $\mathrm{U}_{\mathrm{i}}>0$, $\mathrm{U}_{\mathrm{j}}>0, \mathrm{U}_{\mathrm{ii}}<0, \mathrm{U}_{\mathrm{jj}}<0$, and $\mathrm{U}_{\mathrm{ij}}=\mathrm{U}_{\mathrm{ji}}>0$, given continuity. The utility function is assumed to be homogeneous to the first degree (for example, $U=Y^{a} R^{b}$, where coefficients $a+b=1$ and $a>0$ and $b>0$ ). These properties will be useful when examining the empirical behavior of the income/reserve ratios.

\section{Empirical Analysis}

Country data on income and reserves are taken from the IMF. The reserves are in current US dollars. The income data are in the national currency which was converted to US dollars by the authors using year-end exchange rates contained in the data set. Both variables are in nominal values, but since a ratio $Y / R$ is used, no real value conversion is needed. The countries selected are in two groups, developing economies in South-East Asia (Indonesia, South Korea, Thailand, Singapore, Malaysia, the Philippines, and China-the order follows the order in the Figure 1) and mature economies that are the major trading partners with these economies (Japan, Germany, and the USA in Figure 2). 


\section{Developing Economies}

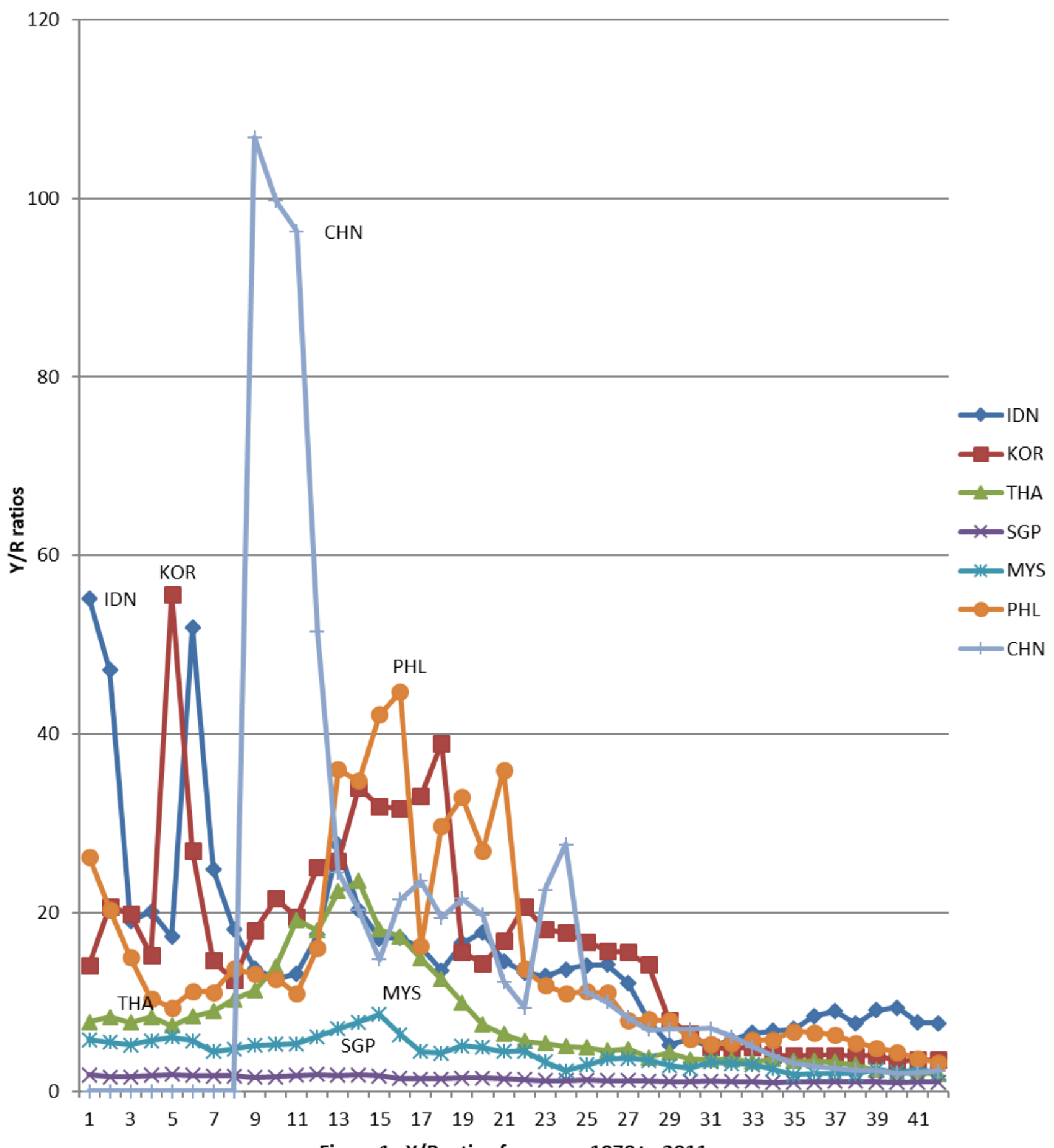

Figure 1. Y/R ratios for year $=1970$ to 2011 


\section{Mature Economies}

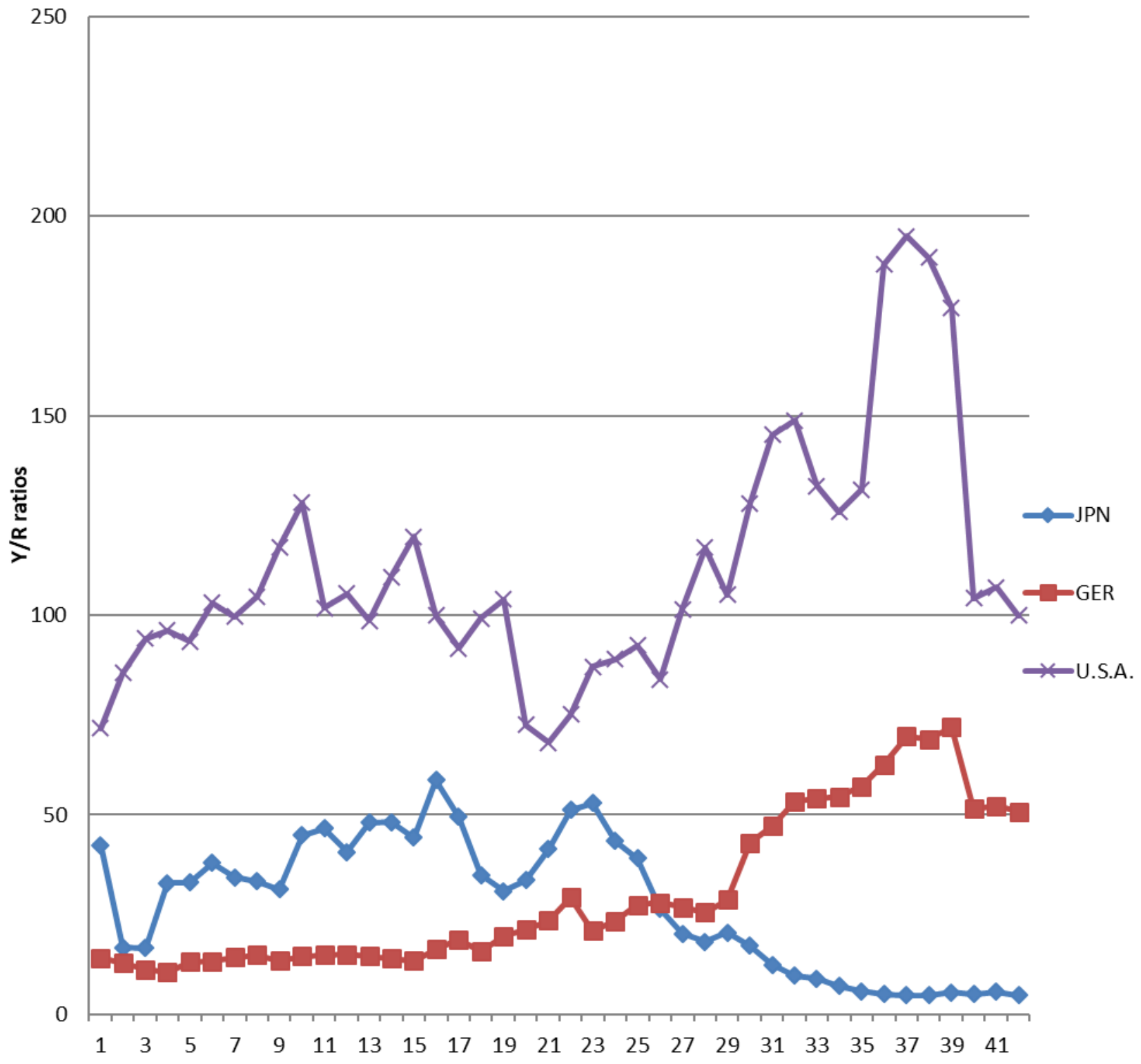

Fig.2. Y/R ratios for years 1970 to 2011

Figure 1 shows the time path of the Y/R ratio for the developing economies. While there exists volatility in the seven time series, since around 1982-1985 the trend is decidedly downward due to the fact that $\mathrm{R}$ is growing faster than Y. To give a sense of the magnitudes of the ratios observed, by order of the appearances in Figure 1, the ratios of $Y / R$ range (from early periods to later) from about 55 to 5,56 to 3,24 to 2,2 to 1,9 to 2,45 to 3 , and 107 to 2 for China. This downward trend in the Y/R ratios is consistent with what others have observed (for example, Jeanne (2007) using the inverse, R/Y, shows an upward trend for emerging markets).

On the other hand, for the mature economies in Figure 2, with the exception of Japan, the trend is decidedly upwards. For Japan, the time series trend is downwards. The ratios range (from the early to the later period) from 59 to 5 for Japan, 11 to 72 for Germany and 72 to 190 for the USA. These empirical results for mature countries are consistent with those shown by Vujanovic (2011). 
What is the economic explanation in terms of the utility function of these results? If $b>a$, this will result in a falling Y/R ratio over time. To see this, we use the two marginals of the utility function, $M U(Y)$ and MU(R), to obtain stylistically, $(\mathrm{b} / \mathrm{a})\left(\mathrm{Y}^{*} / \mathrm{R}^{*}\right)=\mathrm{k}$, where $\mathrm{k}$ is some given constant and $\mathrm{Y}^{*}(\mathrm{t})$ and $\mathrm{R}^{*}(\mathrm{t})$ are the optimal time paths. If $b=a$, then, with $Y^{*}$ and $R^{*}$ growing at the same rate, the ratio remains constant at $k$. With $b>a$, say, $2 / 3$ and $1 / 3$ respectively, then $(b / a)=2$ and the ratio $Y^{*} / R^{*}<k$, implying $R^{*}$ is growing faster than $Y^{*}$, so the ratio $Y / R$ is falling over time (the developing economy case). Alternatively, with $\mathrm{b}<\mathrm{a}$, the ratio $\mathrm{Y}^{*} / \mathrm{R}^{*}>\mathrm{k}$, implying $\mathrm{Y}^{*}$ is growing faster than $\mathrm{R}^{*}$, so the ratio $\mathrm{Y} / \mathrm{R}$ is rising over time (the developed economy ex-Japan case).

For the developing economies, the results mean that they put relatively greater utility (welfare) value on reserves compared to national income. In terms of our model, conceptually, from the previous specification of $U=Y^{a} R^{b}$, if $\mathrm{b}>\mathrm{a}$, then $\mathrm{R}(\mathrm{t})$ is relatively more efficient (the elasticity with respect to $\mathrm{U}($.) is $\mathrm{b}$ ) in generating utility compared to $\mathrm{Y}(\mathrm{t})$. So, while both $\mathrm{Y}$ and $\mathrm{R}$ can be increasing over time (albeit, at different rates), the ratio $\mathrm{Y} / \mathrm{R}$ will be falling over time. It appears that such is the case for the developing economies. The opposite is the case for the mature economies ex-Japan.

The idea that countries hold more reserves relative to income because reserves are more efficient in producing utility still leaves open the question: Why are reserves relatively more efficient (relatively more satisfying) for developing economies? Alfaro and Kanczuk (2006) argue in their stochastic model that the optimal policy is to hold no reserves. Others, for example, Calvo, Izquierdo, and Loo-Kung (2012) and Jeanne (2007) take the position that reserves are needed to finance imports as insurance against a sudden fall in exports.

There is some evidence for the insurance explanation in the data, since the $Y / R$ ratio for the developing economies is lower than that for the developed countries. The developing economies are thus holding more "insurance" relative to income (Y) than the developed economies. Presumably, the developing economies benefit from such insurance to a greater extent than the developed economies. But the problem is that the developing nations are holding vastly more reserves over time, as their economies are growing. If their need for insurance were driven by their (small) size, we would expect this need to decline with growth (i.e., for Y/R to increase over time). This is not the case.

An alternative explanation is that the higher reserves preferred by developing economies is driven by their reliance on exports, which increase along with income (Y). However, the time series in Figure 1 correspond to a period of growing domestic markets in all of these developing economies, particularly South Korea and China, suggesting limits to this explanation as well.

Greater insight can be garnered by examining differences among the developed economies. Holding income constant, Germany's economy is fairly similar to that of the United States; yet Germans have consistently chosen a more conservative level of reserves, resulting in a much lower Y/R ratio. The case of Japan is even more dramatic, with a time-trend that is virtually equivalent (if less volatile) to its Asian neighbors. This trend is so different from the other developed economies that it is unlikely to be explained by variables other than differences in underlying utility.

These facts suggest that culture is likely to play a larger role in shaping the utility derived from reserves than recognized in the literature. Differences in financial attitudes and cultural perspectives toward risk taking across economies and regions can dramatically alter the efficiency with which reserves produce utility.

\section{Summary and Conclusions}

The empirical behavior of national income relative to international reserves was modeled by a utility function model. Fairly standard assumptions were used. The changing ratios over time are trending downwards for developing economies and upwards for mature economies, with the notable exception of Japan. These results are difficult to reconcile with common explanations in the literature, but are consistent with a utility model which allows cultural differences in preferences.

The model was not intended to address specifically how policy outcomes (such as fiscal and monetary changes) are used to control ratios or why different utility functions exist across different types of economies (mature versus developing). The facts show that they do differ and the model does offer an avenue of explanation for the difference. 


\section{References}

Alfaro, L., Kanczuk, F. (2009). Optimal reserve management and sovereign debt. Journal of International Economics, 77, 23-36.

Bar-Ilan, A., Marion, N., Perry, D. (2007). Drift control of international reserves. Journal of Economic Dynamics and Control, 31, 3110-3137.

Calvo, G., Izzquierdo, A., Loo-Kung, R. (2012). Optimal holdings of international reserves: Self-insurance against sudden stop. National Bureau of Economic Research Working Paper 18219, July.

Costinot, A., Lorenzoni, G., Werning, I. (2011). A theory of capital controls as dynamic terms-of-trade manipulation. National Bureau of Economic Research WorkingPaper 17680, December.

Jeanne, O. (2007). International reserves in emerging market countries: Too much of a good thing? Brookings Papers on Economic Activity, 1, 1-79.

Obstfeld, M., Shambaugh, J., Taylor, A. (2008). Financial stability, the trilemma, and international reserves. National Bureau of Economic Research Working Paper 14217, August.

Obstfeld, M., Shambaugh, J., Taylor, A. (2010). Financial stability, the trilemma, and international reserves. American Economic Journal: Macroeconomics, 2(2), 57-95.

Moghadam, R. (2010). Reserve accumulation and international monetary stability. International Monetary Fund, prepared by the Strategy, Policy and Review Department, April, 1-35.

Vujanovic, P. (2011). Understanding the recent surge in the accumulation of international reserves. OECD Economics Department Working Papers, No. 866, May, 1-28. 